\title{
Epidemiology of Chronic Kidney Diseases (CKD) in Malaysia and Pakistan, Pathophysiology of CKD-Associated Pruritus and Other CKD-Associated Dermatological Disorders
}

\author{
Inayat Ur Rehman ${ }^{1,2 *}$, Tahir Mehmood Khan ${ }^{3,4}$ \\ ${ }^{1}$ Department of Pharmacy, Green Campus, Abdul Wali Khan University Mardan, Pakistan \\ ${ }^{2}$ Novel Bacteria and Drug Discovery (NBDD) Research Group, Microbiome and Bioresource Research Strength (MBRS), \\ Jeffrey Cheah School of Medicine and Health Sciences, Monash University Malaysia, 47500 Bandar Sunway, Selangor \\ Darul Ehsan, Malaysia \\ ${ }^{3}$ Institute of Pharmaceutical Sciences (IPS), University of Veterinary \& Animal Sciences (UVAS), Pakistan \\ ${ }^{4}$ Biofunctional Molecule Exploratory Research Group (BMEX), School of Pharmacy, Monash University Malaysia, 47500 \\ Bandar Sunway, Selangor Darul Ehsan, Malaysia
}

\begin{abstract}
Almost 50-90\% of chronic kidney disease patients undergoing haemodialysis have been reported to have Chronic kidney disease-associated pruritus (CKD-aP). The intensity of CKD-aP may vary from a mild itch to an unbearable pruritic sensation which interferes with the patient's quality of life. CKD-aP has become one of the upmost distressing cutaneous and most common symptom of chronic kidney disease which is often overlooked by nephrologists, primary care physicians, and other health-care professionals. Typically sleep disorders, mental and social well-being have been correlated with chronic kidney disease patients. With that this article presents vital comprehensive review which includes epidemiology of chronic kidney disease in Malaysia and Pakistan, CKD-associated pruritus and other dermatological disorders associated with chronic kidney diseases, pathophysiology of CKD-associated pruritus, clinical features of chronic kidney disease-associated pruritus, diagnosis of CKD-associated uremic pruritus, differential diagnosis of CKD-associated uremic pruritus, assessment and quantification of pruritus severity.
\end{abstract}

Keywords: Chronic Kidney Diseases (CKD); Malaysia; Pakistan; pathophysiology of CKD-associated pruritus

Received: $23^{\text {th }}$ Feb 2020

Accepted: $23^{\text {th }}$ March 2020

Published Online: $1^{\text {st }}$ April 2020
*Correspondence: Inayat Ur Rehman, Department of Pharmacy, Green Campus, Abdul Wali Khan University Mardan, Pakistan; inayat.rehman@monash. edu.

Citation: Rehman IU and Khan TM. Epidemiology of Chronic Kidney Diseases (CKD) in Malaysia and Pakistan, pathophysiology of CKD-associated pruritus and other CKD-associated dermatological disorders. Prog Microbes Mol Biol, 2020; 3(1): a0000063. https://doi.org/10.3687/pmmb.a0000063.

\section{INTRODUCTION}

In Malaysia, the prevalence of CKD is on the rise from 13,479 per million populations in year 2004 to 20,589 per million populations in year $2008^{[1]}$. In Malaysia the exact estimation of CKD is unknown, nevertheless the expected incidence of chronic kidney disease in West Malaysia is $9.07 \%{ }^{[2]}$. Additionally, its distribution stage-wise i.e. Stage $1,2,3,4$, and 5 are $4.16 \%, 2.05 \%, 2.26 \%, 0.24 \%$, and $0.36 \%$, respectively ${ }^{[2]}$. According to the $21^{\text {st }}$ report of Malaysian dialysis and transplant registry, the number of patients on dialysis increased from 13,356 in year 2004 to 34,767 in year $2014^{[3]}$.

In Pakistan, chronic kidney disease is progressing, and multiple factors are responsible for this epidemic such as poor health care facility, deficient primary health care system, no proper health education, insufficient funding and higher prevalence of diabetes and hypertension ${ }^{[4]}$.

\section{DEFINITION AND STAGES OF CHRONIC KIDNEY DISEASE (CKD)}

Kidney Disease Outcome Quality Initiative (KDOQI) defines chronic kidney disease (CKD) as an immediate or continuing to decrease kidney function or efficiency for a duration exceeding three months ${ }^{[5]}$. The standards for assessing the disease initiation are mainly urinary outcome, proteinuria and hematuria ${ }^{[6,7]}$. In some cases, the initial presentations are temporary and can be solved by early initiation of drug therapy while in the majority 
of conditions, the decrease in the creatinine clearance and accumulation of waste products like urea and uric acid occurs $^{[7]}$. Glomerular filtration rate (GFR) and creatinine clearance (CC) are two parameters used for estimation of kidney function ${ }^{[5,8]}$. "Glomerular Filtration Rate (GFR) can be defined as the amount of blood that is filtered by Bowman's capsule per unit of time $\left(\mathrm{mL} / \mathrm{min} / 1.73 \mathrm{~m}^{2}\right)$ ". For a healthy human being the GFR values should be range from $120-130 \mathrm{~mL} / \mathrm{min} / 1.73 \mathrm{~m}^{2[8]}$. Listed here are two most common equations used in practice for estimating GFR based on serum creatinine (Scrt).

1. Cockcroft-Gault equation ${ }^{[9]}$

2. Modification of Diet in Renal Disease (MDRD) equation $^{[10]}$

\section{Cockcroft-Gault Equation}

$\mathrm{CC}(\mathrm{mL} / \mathrm{min})=([140-$ Age $\times$ weight $] /[72 \times$ Scrt $]) \times$ 0.85 if female

\section{MDRD Equation}

eGFR $\left(\mathrm{mL} / \mathrm{min} / 1.73 \mathrm{~m}^{2}\right)=186 \times[$ Scrt $]-1.154 \times[$ Age $]$ $-0.203 \times[0.742$ if female $]$

Note: for African/ Black use the multiplication factor 1.21

\section{Stages of kidney diseases:}

On the basis of Creatinine Clearance (CC) or estimated Glomerular Filtration Rate (eGFR) kidney disease can be classified in five stages ${ }^{[5,11]}$ :

i. Stage 1: Normal or increased GFR i.e. 90 or more $\mathrm{mL} / \mathrm{minute} / 1.73 \mathrm{~m}^{2}$

ii. Stage 2: Mild decrease in GFR i.e. $60-89 \mathrm{~mL} /$ minute $/ 1.73 \mathrm{~m}^{2}$

iii. Stage 3: Moderate decrease in GFR i.e. $30-59 \mathrm{~mL} /$ minute $/ 1.73 \mathrm{~m}^{2}$

iv. Stage 4: Severe decrease in GFR i.e. $15-29 \mathrm{~mL} /$ minute $/ 1.73 \mathrm{~m}^{2}$

v. Stage 5: Kidney failure i.e. Less than $15 \mathrm{~mL} /$ minute $/ 1.73 \mathrm{~m}^{2}$ or on dialysis

Creatinine is basically a by-product that forms from protein metabolism. When the kidney function starts deteriorating, clearance from kidney reduces which leads to an elevated serum creatinine, uric acid and urea ${ }^{[9]}$. Majority of the patients at stage 4 and stage 5 of kidney diseases get frequent dialysis based on their renal reservoir. In general, most of the patients get dialysis three times a week. The main aim for performing dialysis is to eliminate the waste products from the blood such as urea, uric acid, nitrogen and excessive electrolytes.

Low GFR alone is not confirmatory for diagnosis of $\mathrm{CKD}$, as it may be borderline normal or normal. In order to establish the diagnosis for CKD, the presence of one or more markers as listed is vital[ ${ }^{[12]}$.
- Histological abnormalities

- Urine sediment abnormalities

- Albuminuria (albumin excretion $>30 \mathrm{mg} / 24 \mathrm{hr}$ )

- Electrolyte and other abnormalities owing to tubular disorders

- Renal transplantation history

- Structural abnormalities detected by imaging

\section{EPIDEMIOLOGY OF CKD}

CKD is currently one of most serious health crises. Epidemiological data suggests that CKD is a big threat globally for both developing and developed countries ${ }^{[13]}$. According to 2010 statistic of Global Burden of Disease (GBD), among the directory causes of global deaths, CKD was categorized $27^{\text {th }}$ in 1990 but due to its higher prevalence, it climbed to $18^{\text {th }}$ in $2010^{[14]}$. The 2013 statistic by Global Burden of Disease (GBD), comparing the mortality rate of CKD patients between 1990 and 2013, indicates mortality rate is increased by $134.6 \%$ in 2013 compared to $1990^{[15]}$. The prevalence of CKD is heterogeneous globally, with the incidence of CKD was higher in Indo-Asians population as compared to the European population. The statistics indicated CKD is more prevalent in Asian countries as compared to the rest of the world. Malaysia reported prevalence of $9.07 \%{ }^{[2]}$, while China and Nepal reported prevalence of $10-19 \% \%^{[16]}$ and $10-20 \%{ }^{[17]}$ respectively. Whereas Pakistan, Bangladesh, and India reported prevalence of $20 \%{ }^{[18-20]}$. One possible reasons for the increased in prevalence is the reduced access to preventative health care, which helps to reduce the progression of kidney diseases $^{[21]}$. Furthermore the global increase in CKD cases and its progression toward end-stage renal disease due to global increase of diabetes and hypertension pandemics [22-24].

\section{Chronic kidney diseases in Malaysia}

In Malaysia, the prevalence of CKD is increasing from 13,479 per million populations in 2004 to 20,589 per million populations $2008^{[1]}$. In Malaysia the exact estimation of CKD is unknown, still the expected incidence of chronic kidney disease in West Malaysia is $9.07 \%{ }^{[2]}$. Moreover, its distribution stage-wise i.e. stage 1, 2, 3, 4 , and 5 are $4.16 \%, 2.05 \%, 2.26 \%, 0.24 \%$, and $0.36 \%$, respectively[2]. The $21^{\text {st }}$ report of Malaysian dialysis and transplant registry stated the number of patients on dialysis increased from 13,356 in 2004 to 34,767 in $2014^{[3]}$, as depicted in Figure 1. The acceptance rate and prevalence rate of dialysis are 210 and 1065 per million populations respectively ${ }^{[1]}$. The report stated that overall acceptance and prevalence rate of dialysis is almost doubled during the span of 10 years $^{[1]}$. States in Malaysia which are economically advanced have a much higher rate of dialysis treatment compared to those states which are economically less advanced. Approximately $90 \%$ of new dialysis patients are accepted into haemodialysis center and the rest into the peritoneal dialysis program ${ }^{[1]}$. In 2013 , the annual death rate on dialysis was reported as $11.3 \%$, out of which $10.9 \%$ were of haemodialysis and $15.8 \%$ were of peritoneal dialysis ${ }^{[1]}$. Diabetes is considered to be the typical cause of $\mathrm{CKD}$, with reported cases of $\mathrm{CKD}$ due 
to diabetes at 53\% in 2004 and $61 \%$ in $2013^{[1]}$. End stage renal disease caused by diabetes has increased dramatically and is accountable for $50 \%$ incidents in dialysis patients. The Malaysian National Registry estimated the prevalence of end-stage renal disease in 2007 will be 680 per million population ${ }^{[25]}$. According to National Renal
Registry Malaysia $(2015)^{[3]}, 32,026$ patients were on dialysis; of whom $91 \%$ were on haemodialysis and $9 \%$ were on peritoneal dialysis. It has been estimated that by 2040 , the number of patients with end stage renal disease would triple from existing 2014 cases $^{[26]}$. Ibrahim et al. $(2011)^{[27]}$ reported the prevalence of CKD-aP in Malaysia by $64.2 \%$ and sleep disturbance with $61.7 \%$ in CKD patients.

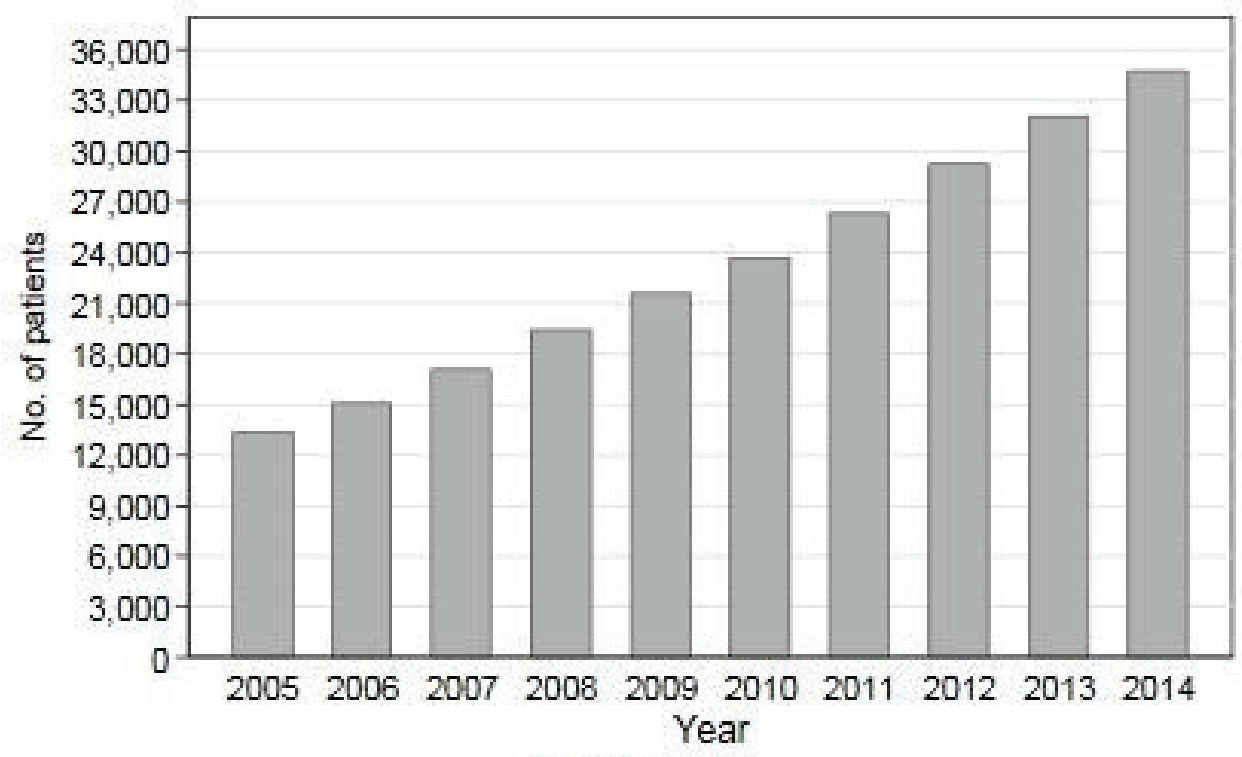

Dec 2005-2014

Figure 1. Statistic of increase in dialysis patients indicating an increase during December 2005- December 2014 in Malaysia.

\section{Chronic kidney disease in Pakistan}

In Pakistan, chronic kidney disease is progressing with multiple factors responsible for this epidemic such as poor health care facility due to deficient primary health care system, no proper health education, insufficient government funding and higher occurrence of diabetes and hypertension marked as a high-risk factor for $\mathrm{CKD}^{[4]}$. In Pakistan, the absence of periodically maintained central registry kidney diseases on a national level about its epidemiological and burden makes it extremely difficult to assess the cases of CKD, dialysis, mortality, and allocation of the fund in Pakistan ${ }^{[4]}$. Data from the Dialysis Registry of Pakistan 2007-2008 indicated the number of CKD patients increased from 4,393 in 2006-2007 to 6,127 in 2007-2008 ${ }^{[28]}$. While current data indicated 16,000 Pakistanis suffer from CKD annually and Pakistan is ranked the eighth in the world on basis of highest number of epidemiology and prevalent cases of CKD ${ }^{[29]}$. Jessani et al. $(2014)^{[19]}$ reported that CKD prevalence in Karachi is $12.5 \%$. While Luqman et al. $(2012)^{[30]}$ reported the prevalence of CKD in Pakistan as 64\%.

\section{CKD-ASSOCIATED PRURITUS (CKD-aP) AND OTHER DERMATOLOGICAL DISOR- DERS ASSOCIATED WITH CHRONIC KID- NEY DISEASES}

Dermatological disorders are regularly observed in CKD patients. Skin-associated problems like CKD-aP, xerosis, pallor, and hyperpigmentation are very common in CKD patients $^{[31]}$. Most often, in the case of renal failure, the skin becomes an excretory organ for the substances the kidney usually clears from the body. A study on dermatological problems associated with CKD indicated the prevalence of skin conditions observed were pallor $91.5 \%$, xerosis $75.9 \%$, pigmentary changes $65 \%$, CKD-aP $60.2 \%$ and panniculitis $1.2 \%{ }^{[31]}$. CKD-aP is a commonly found complication reported by majority of chronic kidney disease patients ${ }^{[32]}$. The prevalence of CKD-aP was found to be more in haemodialysis patients $(68 \%)$ than in peritoneal dialysis patients $(38 \%)$ [33]. The occurrence of CKD-aP in CKD patients differ extensively from $22 \%$ to $90 \%{ }^{[34-38]}$. Normally, the whole body is affected while the back and forearms are most likely to get affected compared to other parts of the body. Severe CKDaP has a major impact on the patient's life quality which leads to other disorders such as anxiety, disturbed sleep, and depression ${ }^{[39-43]}$. Recently two studies (a Japanese study and the DOPPS) demonstrated a relationship between CKD-aP and an amplified threat of mortality ${ }^{[34,38]}$. Several studies report a considerable prevalence of CKD-aP among dialysis patients, ranging from $10 \%$ to $70 \%$ in PD patients and $20 \%$ to $90 \%$ in HD patients ${ }^{[44]}$. Almost $50 \%$ or greater chronic kidney disease patients are reported of having the dermatological problem like dry skin and itching ${ }^{[45]}$. These associated dermatological problems have a significant impact on quality of life which negatively impacted on CKD patients' physical and mental health ${ }^{[31]}$.

Pruritus is linked with some other metabolic changes which 
trigger and potentiate it, such as xerosis, decreased transepidermal elimination of pruritogenic factors, hyperparathyroidism, hypercalcemia and hypophosphatemia, higher levels of histamine and transdermal mast cell proliferation, and uremic sensory neuropathy ${ }^{[46]}$. In parallel to internal factors, few external factors are also hypothesized to be related with pruritus, such as dehydration, excessive sweating, humid and hot weather, shower with cold/hot water and stress ${ }^{[46]}$. Also CKD-aP patients could experience abnormal skin pigmentation and low platelet counts as a result of prolonged bleeding ${ }^{[47]}$. Usually after a temporary relief from pruritus, the symptoms reappear within six months with much-intensified degree regardless of any demographic variables ${ }^{[46]}$. CKD-aP occurs intermittently in some cases that may last for few minutes while some patients suffer from lengthy phases of severe CKD-aP that may be present during both day and night ${ }^{[45]}$. CKD-aP onset, duration, and intensity can change over time and the itching is usually worsened at night time. Most normally affected body parts by CKD-aP are the back, limbs, chest, and head, however, approximately $20-50 \%$ of patients experience a generalized $\mathrm{CKD}-\mathrm{aP}^{[38]}$.

\section{PATHOPHYSIOLOGY OF CKD-ASSOCIATED PRURITUS (CKD-aP)}

The exact mechanism associated with the pathophysiology of CKD-aP is poorly understood. Several hypotheses are discussed in this article for the pathophysiology of CKDaP.

\section{Immune-mediated hypothesis}

CKD-aP is potentially due to dysregulated systemic inflammation $^{[48-50]}$. In CKD-aP patient's elevated levels of T-helper type-1 cells ${ }^{[49]}$, interleukin-6 ${ }^{[49]}$, interleukin- $2^{[50]}$ and C-reactive protein ${ }^{[51]}$ were observed. It is recommended that CKD-aP is associated with high white blood cell count, high ferritin level and low albumin level ${ }^{[51]}$. The immune hypothesis refers CKD-aP as overproduction of proinflammatory substances such as histamine (by mast cells), interleukin 2, tumor necrosis factor $\alpha$ and interferon $\gamma$ by T Helper 1 lymphocytes ${ }^{[52,53]}$; elevated level of inflammatory markers such as C-reactive protein and interleukin $6^{[50,54,55]}$. The elevated levels of serine protease and Proteinase-Activated Receptor- 2 could also play vital roles in the pathogenesis of CKD-aP ${ }^{[56]}$.

\section{Xerosis hypothesis}

Xerosis (dry skin), is another common dermatological condition reported in patients with $\mathrm{CKD}^{[57,58]}$. The reduction of the eccrine sweat glands size and the atrophy of the sebaceous glands are assumed as the main reasons for xerosis $^{[59]}$. Xerosis has been considered as a substantial contributor in CKD-aP severity ${ }^{[60]}$.

\section{Histamine hypothesis}

The increased of mast cells and histamine levels ${ }^{[61-63]}, \mathrm{Se}-$ rotonin level ${ }^{[64]}$, eosinophil's and tryptase have been witnessed in patients with CKD-aP ${ }^{[61,62]}$. Nevertheless, Prasad et al. (2015) reported that despite increased mast cells and histamine levels there was no direct correlation between histamine level and CKD-aP.

\section{Neuropathic hypothesis}

The neuropathic hypothesis suggests that the somatic and autonomic neuropathy caused by lesion can result in neuropathic itch ${ }^{[65,66]}$. It is recognized that neuropathic pain and pruritus shared the same neuronal pathway ${ }^{[67]}$. The involvement of neuropathic mechanisms in the mediation of pruritus is further demonstrated with gabapentin and pregabalin that are effective in the improvement of the patient with pruritus ${ }^{[68,69]}$. This also advocated that afferent $\mathrm{C}$-terminal nerve fibers that are GABA-aminobutyric acid (GABA) dependent is involved in the CKD$\mathrm{aP}^{[70]}$.

\section{Opioid hypothesis}

The opioid hypothesis suggests that the imbalance of endogenous opioidergic system plays an important role in the pathophysiological mechanism of pruritus by the ability of $\mu$ receptor antagonists and $x$ receptor agonists in relieving itchiness ${ }^{[67,71,72]}$. The $\mu$-opioid receptor activation is involved in the intervention of pruritus while $x$-opioid receptor activation has an inhibitory effect on $\mu$-opioid receptor both peripherally and centrally ${ }^{[67,72-74]}$.

\section{Hyperparathyroidism hypothesis}

The hyperparathyroidism is expected to play a role in pruritus through inducing mast cell secretion ${ }^{[75]}$. Secondary parathyroidectomy trigger elevation of divalent ions such as magnesium, phosphate, and calcium, this could result in micro-precipitation that is known to have affect the modulation of mast cells degranulation ${ }^{[76]}$. Low serum phosphorus level was recently found to be significantly lower in haemodialysis patients with severe and frequent $\mathrm{CKD}-\mathrm{aP}$ as compared to those without CKD-aP ${ }^{[77]}$.

\section{Other factors}

Other factors associated with CKD-aP include the production of pruritogenic substances such as abnormal growth, cytokines, and sprouting of "itch fibers" in the skin, also neuropathy that leads to the decreased of the threshold for itch sensation ${ }^{[78,79]}$.

\section{CLINICAL FEATURES OF CKD-aP}

Clinical characteristic varies for each patient and over time among patients. As the CKD-aP onset, intensity and duration can change over time ${ }^{[37]}$, and the itch is typically worsened at night time ${ }^{[45]}$. CKD-aP could be generalized or localized; however back, abdomen and forearms are most likely to be affected compared to other parts of the body ${ }^{[38,45]}$. Other characteristics include:

- Worsen in itch intensity at night and cause sleep disturbance ${ }^{[34,38,45,80,81]}$.

- Xerosis (dry skin), skin scaling and epidermal cracking $^{[60]}$.

- Elevated blood urea nitrogen (BUN), calcium, phosphate, and magnesium and parathyroid hormone (PTH), levels ${ }^{[34]}$.

- $\quad$ Fatigue and depression ${ }^{[38,82]}$. 


\section{DIAGNOSIS OF CKD-aP}

$\mathrm{CKD}-\mathrm{aP}$ is one of the most common complication reported by CKD patients on haemodialysis, so the diagnosis is easy unless there is other compelling evidence of other causes. The most common suggestive diagnosis characteristic of CKD-aP is its occurrence after the imitation of haemodialysis. Also, elevated calcium, magnesium, phosphate, blood urea nitrogen (BUN) and parathyroid hormone (PTH) levels ${ }^{[34]}$ were confirmed among CKD-aP patients on haemodialysis.

\section{Differential diagnosis of CKD-aP}

Several diseases could cause CKD-aP in patients with and without $\mathrm{CKD}$. In order to confirm $\mathrm{CKD}-\mathrm{aP}$, a non-uremic cause of CKD-aP should be kept in thought among patients on haemodialysis with symptoms that are refractory to common treatments such as an oral antihistamines, gabapentin, analgesic agents and topical emollient ${ }^{[83]}$.

\section{ASSESSMENT AND QUANTIFICATION OF CKD-aP SEVERITY}

CKD-aP has become one of the most distressing cutaneous, and the most common symptom of CKD that is commonly overlooked by nephrologists, primary care physicians, and other health-care professionals ${ }^{[46]}$. To assess the severity of CKD-aP, several instruments have been developed and these tools shall be illustrated in this review.

The literature showed that the rating scales are commonly used for assessment and quantification of CKD-aP. The rating scales/tools includes verbal rating scale (VRS), visual analogue scale (VAS), numerical rating scale (NRS), Eppendorf itch questionnaire (EIQ), Dermatology quality of life questionnaire (DLQI) and 5Ditch scale (5D-IS), Modified pruritus questionnaire for itch severity score, Skindex( Skindex-29 and Skindex-16) ${ }^{[84-91]}$.

\section{Visual analogue scale (VAS)}

Visual analogue scale is a unidimensional scale that is an easy and rapid tool commonly used for assessment of pruritus severity ${ }^{[71]}$. The VAS consists of a $10 \mathrm{~mm}$ horizontal line indicating the severity of itch; "no itch" (o points) and ending with "worst itching"[92]. The evaluation of CKDaP relying on a single measure is not sufficient, VAS is a useful tool for the assessment of pruritus intensity but it does not provide any further information on other aspects of CKD-aP ${ }^{[93]}$.

\section{Verbal rating scale (VRS)}

Verbal rating scale (VRS) is another unidimensional tool for assessment of pruritus that assists the patient to verbally describe the degree of pruritus. This is possibly the most convenient method for assessment of pruritus; with four-point scale "none, mild, moderate and severe pruritus" "[94] and five-item scale "none, mild, moderate, severe and very severe pruritus" ${ }^{[95]}$ are used for assessment of pruritus. The variability in different versions of VRS point scale contributes toward a major limitation of this scale, thus making the comparison of these results very diffi- cult ${ }^{[96]}$. However, VRS has the advantage as one of the most suitable tool for assessment of $\mathrm{CKD}-\mathrm{aP}$ in certain populations such as elderly or patients with cognitive problems ${ }^{[96]}$.

\section{Eppendorf itch questionnaire (EIQ)}

The Eppendorf itch questionnaire was developed by Darsow et al. (2001) ${ }^{[97]}$, for the exact characteristic of pruritus using a comprehensive list of sensory and affective descriptors, and also collects evidence on the impact of pruritus on quality of life ${ }^{[97]}$.

\section{Dermatology quality of life questionnaire (DLQI)}

The Dermatology Life Quality Index, the first dermatology was by Finlay and Khan (1994) ${ }^{[98]}$, and contains 10 questions concerning "symptoms and feelings, daily activities, leisure, work, and school, personal relationships and treatment" over previous one week. The responses for this tool are ranged from 0 to 3 "not at all", "a little", "a lot" or "very much" respectively. Each response is scored from 0 to 3 and then summed up, score of 0 indicates no impairment of life quality while score of 30 indicates maximum impairment ${ }^{[98]}$.

\section{D-itch scale (5D-IS)}

A 5D-itch scale is a multidimensional tool, that comprises of five domains, addressing the "duration, degree, direction, disability, and distribution of itching" "[87]. The duration, degree and direction domains each included one item, while the disability domain had four items. All items of the first four domains were measured on a five-point Likert scale (where 1 represented the lowest degree of pruritus, and 5 represented the highest degree). The $4^{\text {th }}$ domain (disability) measured the effect of itching on daily activities, and its score was calculated by selecting the highest score. In the $5^{\text {th }}$ domain, participants were asked to select which part of the body was most affected by CKD-aP, and participants could select as many body parts as they wished. If two body parts were affected, the score given was $1 ; 3-5$ body parts affected was scored as 2, 6-10 body parts were scored as 3, $11-13$ body parts were scored as 4 , and $14-16$ body parts were scored as 5 . The overall score of the 5D-IS was calculated with all the five domains; 5 indicates no pruritus; whilst a score of 25 indicates severe pruritus ${ }^{[87]}$.

\section{Modified pruritus questionnaire for itch severity score}

The Itch severity scale developed by ${ }^{[81]}$ for evaluation of pruritus was modified by ${ }^{[8]}$, as the questionnaire by Yosipovitch et al. $(2001)^{[81]}$ has no method of scoring for quantification of symptom severity. The modified questionnaire by Majeski et al. (2007) ${ }^{[8]}$ consists of 7 components: "frequency, itch description, affected body surface area, intensity, the effect on mood, an effect on sexual desire/function and effect on sleep". The responses to a different component of the questionnaire were separately summed and divided by a maximum score for the respective question. All the seven values achieved were then added and multiplied by 3 to get a total out of 21 scores. The yielding total scores ranging from 0 to $21^{[88]}$. 


\section{Skindex questionnaire}

Skindex is among the best dermatological instruments for the measurement of dermatological specific health related quality of life (QOL) $)^{[89]}$. Skindex was originally comprised of 61 questions that were later on divided into two brief versions i.e. Skindex $16^{[91]}$ and Skindex 29 ${ }^{[90]}$. The Skindex-29 is instruments of choice in dermatology ${ }^{[99]}$, it is comprised of 7 items addressing the symptoms domain, 10 items for the emotional domain, and 12 items for the functioning domain. The responses of all domains were transformed to a linear scale of 100, varying from 0 (no effect) to 100 (effect experienced all the time) ${ }^{[100]}$. Whereas Skindex-16 is a single page questionnaire, that is an accurate and sensitive measurement for patients experience and widely used for skin-related quality of life ${ }^{[101,102]}$. The Skindex-16 comprised of 4 items related to symptoms, 7 items related to emotions and 5 items related to functioning scales and linear scale of 100 , varying from 0 (no effect) to

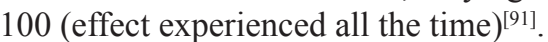

\section{CONCLUSION}

Researchers reported the prevalence of CKD-aP was slightly higher in Pakistani patients when compared to Malaysian patients. Prevalence studies in Pakistan reported rates of $64.0 \%$ to $77.7 \%{ }^{[30,103,104]}$ while Malaysia studies reported rates of $58.6 \%$ to $64.2 \%{ }^{[27,105]}$. The pruritus median score was also significantly higher in Pakistani 10.0 [8.0-12.0] compared to Malaysian patients 8.0 [6.0-9.0]; $p=<0.001$. The possible reasons for the variation in the prevalence of CKD-associated pruritus between Malaysian and Pakistani because patients in Pakistan receive haemodialysis twice/week, whereas in Malaysia, it is three times/ week. Moreover, low to medium flux dialyzers were used in Pakistan, whilst high flux dialyzer (which removes average-sized molecules more effectively - thus reducing the severity of uremic pruritus) was used in Malaysia. CKD-aP is believed to be caused by middle-molecule uremic toxins which are not dialyzed properly when using low flux dialyzer ${ }^{[34]}$. Globally the high-flux haemodialysis is the most commonly used blood purification method. But in developing countries such as Pakistan, low-flux dialysis is the main method of extracorporeal blood purification therapy due to insufficient funds to purchase high flux dialyzers ${ }^{[106]}$. Haemodialysis machines are also limited in Pakistan as in 2004 there were 140 dialysis centers although in 2009 these machines increased to $175^{[107]}$, alarmingly out of the available dialysis centers in Pakistan, $10-15 \%$ are non-functional and the patients have limited access to treatment ${ }^{[107]}$.

The Pakistani patients were significantly younger than Malaysian patients and had a shorter median duration of CKD and being on haemodialysis. This could be due to poorer management of chronic conditions (such as hypertension or diabetes mellitus) which predisposes an individual to renal damage at younger age. Additionally, Pakistani patients may have less knowledge of the complications of their chronic conditions and therefore may not take any preventive measures such as control of hypertension and dietary modifications $^{[108]}$. Malaysian population was graded higher when their knowledge was tested against diabetes and hypertension ${ }^{[109-112]}$, these results were quite different for the Pakistani population ${ }^{[13-116]}$. Furthermore, awareness and attitude also have a decisive role in the actions of diabetic and hypertension patients. In Pakistan, many factors may account for poorer outcomes during dialysis; such as malnutrition, late referral, anaemia and lack of qualified nephrologists at dialysis centers $^{[117-120]}$.

In conclusion, this review provided vital insight on the epidemiology of chronic kidney diseases (CKD) in Malaysia and Pakistan, together with the pathophysiology of CKD-associated pruritus and other CKD-associated dermatological disorders. Both countries could improve the awareness of their populations and providing more support to the healthcare setting to increase the quality of life of CKD patients.

\section{Authors Contributions}

The literature review and manuscript writing were performed by I-UR and T-MK.

\section{Conflict of interest}

The authors declare that there is no conflict of interest in this work.

\section{Reference}

1. National Renal Registry Malaysia. 21st Report of the Malaysian Dialysis and Transplant 2013. 2014; Available from: https://www. crc.gov.my/wpcontent/uploads/documents/report/21stdialysis transplant 2013.pdf [Accessed 28th Janurary 2016].

2. Hooi LS, Ong LM, Ahmad G, et al. A population-based study measuring the prevalence of chronic kidney disease among adults in West Malaysia. Kidney Int, 2013; 84(5): 1034-1040.

3. National Renal Registry Malaysia. 22nd Report of the Malay sian Dialysis and Transplant Registry 2014. 2015; Available from: http://www.msn.org.my/Doc/PublicDoc PB/Publication mdtr22nd/22nd MDTR 2014.pdf [Accessed 28th October 2016]

4. Ullah K, Butt $\overline{\mathrm{G}}$, Masroor I, et al. Epidemiology of chronic kidney disease in a Pakistani population. Saudi J Kidney Dis Transpl, 2015; 26(6): 1307.

5. Foundation NK, Clinical practice guidelines for chronic kidney disease: Evaluation, classification and stratification. 2002: National Kidney Foundation.

6. Keane WF and Eknoyan G. Proteinuria, albuminuria, risk, assessment, detection, elimination (PARADE): A position paper of the National Kidney Foundation. Am J Kidney Dis, 1999; 33(5): 1004-1010.

7. Joy M, Kshirsagar A, and Franceschini N. Chronic kidney disease: Progression-modifying therapies. 7th ed. Pharmacotherapy A Pathophysiologic Approach, ed. J.T. DiPiro, et al. 2008, China: McGraw-Hill. 745-763.

8. Smith HW. The kidney: Structure and function in health and disease. 1951: Oxford University Press, USA.

9. Cockcroft DW and Gault MH. Prediction of creatinine clearance from serum creatinine. Nephron, 1976; 16(1): 31-41.

10. Levey AS, Bosch JP, Lewis JB, et al. A more accurate method to estimate glomerular filtration rate from serum creatinine: A new prediction equation. Ann Intern Med, 99; 130(6): 461-470.

11. DiPiro JT, Talbert RL, Yee G, et al. Pathophysiologic Approach. 2008: McGraw Hill Companies, South Carolina.

12. Levey AS and Coresh J. Chronic kidney disease. Lancet, 2012; 379(9811): 165-180.

13. Jurkovitz CT, Elliott D, Li S, et al. Physician utilization, risk-factor control, and CKD progression among participants in the Kidney Early Evaluation Program (KEEP). Am J Kidney Dis, 2012; 59(3): S24-S33. 
14. Jha V, Garcia-Garcia G, Iseki K, et al. Chronic kidney disease: Global dimension and perspectives. Lancet, 2013; 382(9888): 260-272.

15. Naghavi M, Wang H, Lozano R, et al. GBD 2013 Mortality and causes of death collaborators. Global, regional, and national age-sex specific all-cause and cause-specific mortality for 240 causes of death, 1990-2013: A systematic analysis for the Global Burden of Disease Study 2013. Lancet, 2015; 385(9963): 117-171.

16. Zhang L, Wang F, Wang L, et al. Prevalence of chronic kidney disease in China: A cross-sectional survey. Lancet, 2012; 379(9818): 815-822.

17. Stanifer JW, Muiru A, Jafar TH, et al. Chronic kidney disease in lowand middle-income countries. Nephrol Dial Transpl, 2016; 31(6): 868-874.

18. Anand S, Khanam MA, Saquib J, et al. High prevalence of chronic kidney disease in a community survey of urban Bangladeshis: A cross-sectional study. Glob Health, 2014; 10(1): 1.

19. Jessani S, Bux R, and Jafar TH. Prevalence, determinants, and management of chronic kidney disease in Karachi, Pakistan-A community based cross-sectional study. BMC Nephrol, 2014; 15(1): 1 .

20. Singh AK, Farag YM, Mittal BV, et al. Epidemiology and risk factors of chronic kidney disease in India-results from the SEEK (Screening and Early Evaluation of Kidney Disease) study. BMC Nephrol,2013; 14(1): 1 .

21. Trehan A, Winterbottom J, Lane B, et al. End-stage renal disease in Indo-Asians in the North-West of England. QJM, 2003; 96(7): 499504.

22. Yach D, Hawkes C, Gould CL, et al. The global burden of chronic diseases: Overcoming impediments to prevention and control. JAMA, 2004; 291(21): 2616-2622.

23. Beaglehole R and Yach D. Globalisation and the prevention and control of non-communicable disease: The neglected chronic diseases of adults. Lancet, 2003; 362(9387): 903-908.

24. Ezzati M, Vander Hoorn S, Lawes CM, et al. Rethinking the "diseases of affluence" paradigm: Gobal patterns of nutritional risks in relation to economic development. PLoS Med, 2005; 2(5): e133.

25. Jha V. Current status of chronic kidney disease care in southeast Asia in Semin Nephrol. 2009. Elsevier.

26. Bujang MA, Adnan TH, Hashim NH, et al. Forecasting the incidence and prevalence of patients with end-stage renal disease in Malaysia up to the Year 2040. Int J Nephrol, 2017; 2017.

27. Ibrahim N, Chiew-Tong NK, and Desa A. Symptoms and healthrelated quality of life in patients with heamodialysis and continuous ambulatory peritoneal dialysis. Res J Med Sci, 2011; 5(5): 252-256.

28. Anonymous, KARACHI: Diabetes on the rise, in Daily DAWN. 2008: Pakistan.

29. Anonymous, Check for chronic kidney disease, in Nation newspaper. 2016: Pakistan.

30. Luqman N, Khalid M, and Shaheen JA. Cutaneous manifestations of chronic renal failure in Bahawalpur, Pakistan. J Pak Assoc Dermatol, 2012; 22(3): 219-223.

31. Shah A, Hada R, and Kayastha BMM. Dermatological disorders in chronic kidney disease. J Nepal Med Assoc, 2013; 52(190).

32. Arican O, Pathophysiology. Clinical presentation and management of pruritus. Turkderm, 2005; 39: 88-97.

33. SuSeł J, Batycka-Baran A, Reich A, et al. Uraemic pruritus markedly affects the quality of life and depressive symptoms in haemodialysis patients with end-stage renal disease. Acta Derm Venereol, 2014; 94(3): 276-281.

34. Narita I, Alchi B, Omori K, et al. Etiology and prognostic significance of severe uremic pruritus in chronic hemodialysis patients. Kidney Int, 2006; 69(9): 1626-1632.

35. Ponticelli $\mathrm{C}$ and Bencini P. Uremic pruritus: A review. Nephron, 1992; 60(1): 1-5.

36. Pauli-Magnus C, Mikus G, Alscher DM, et al. Naltrexone does not relieve uremic pruritus results of a randomized, double-blind, placebocontrolled crossover study. J Am Soc Nephrol, 2000; 11(3): 514-519.

37. Young Jr A, Sweeney E, David D, et al. Dermatologic evaluation of pruritus in patients on hemodialysis. N Y State J Med, 1973; 73(22): 2670.

38. Pisoni RL, Wikström B, Elder SJ, et al. Pruritus in haemodialysis patients: International results from the Dialysis Outcomes and Practice Patterns Study (DOPPS). Nephrol Dial Transpl, 2006; 21(12): 3495-3505.

39. Wu C-F, Hsiao Y-C, and Ko P-C. The effects of nonpharmacological treatment on uremic pruritus patients: A systematic review. Adv Nurs, $2015 ; 2015$.

40. Rehman IU, Lai PSM, Lim SK, et al. Sleep disturbance among Malaysian patients with end-stage renal disease with pruritus. BMC Nephrol, 2019; 20(1): 102.

41. Rehman IU, Chan KG, Munib S, et al. The association between CKDassociated pruritus and quality of life in patients undergoing hemodialysis in Pakistan: A STROBE complaint cross-sectional study. Medicine, 2019; 98(36)

42. Rehman IU, Lai PS, Kun LS, et al. Chronic kidney disease $\square$ associated pruritus and quality of life in Malaysian patients undergoing hemodialysis. Ther Apher Dial, 2020; 24(1): 17-25.

43. Rehman IU, Chia DWB, Ahmed R, et al. A randomized controlled trial for effectiveness of zolpidem versus acupressure on sleep in hemodialysis patients having chronic kidney disease-associated pruritus. Medicine, 2018; 97(31)

44. Wu H-Y, Peng Y-S, Chen H-Y, et al. A comparison of uremic pruritus in patients receiving peritoneal dialysis and hemodialysis. Medicine, 2016; 95(9): e2935.

45. Mistik S, Utas S, Ferahbas A, et al. An epidemiology study of pa- tients with uremic pruritus. J Eur Acad Dermatol Venereol, 2006; 20(6) 672-678.

46. Patel TS, Freedman BI, and Yosipovitch G. An update on pruritus associated with CKD. Am J Kidney Dis, 2007; 50(1): 11-20.

47. Chikotas N, Gunderman A, and Oman T. Uremic syndrome and end stage renal disease: Physical manifestations and beyond. J Am Acad Nurse Pract, 2006; 18(5): 195-202.

48. Mettang T and Kremer AE. Uremic pruritus. Kidney Int, 2015; 87(4): 685-691.

49. Kimmel M, Alscher DM, Dunst R, et al. The role of micro-inflammation in the pathogenesis of uraemic pruritus in haemodialysis patients. Nephrol Dial Transpl, 2005; 21(3): 749-755.

50. Fallahzadeh MK, Roozbeh J, Geramizadeh B, et al. Interleukin-2 serum levels are elevated in patients with uremic pruritus: A novel finding with practical implications. Nephrol Dial Transpl, 2011; 26(10): 3338-3344.

51. Shirazian S, Aina O, Park Y, et al. Chronic kidney disease-associated pruritus: Impact on quality of life and current management challenges. Int J Nephrol Renovasc Dis, 2017; 10: 11 .

52. Balaskas EV and Grapsa E. Uremic pruritus is a poor prognostic factor of outcome. Perit Dial Int, 1995; 15(2): 177.

53. Namazi MR, Fallahzadeh MK, and Roozbeh J. Nicotinamide as a potential novel addition to the anti-uremic pruritus weaponry. Saudi J Kidney Dis Transpl, 2009; 20(2): 291-292.

54. Kimmel M, Alscher DM, Dunst R, et al. The role of micro-inflammation in the pathogenesis of uraemic pruritus in haemodialysis patients. Nephrol Dial Transplant, 2006; 21(3): 749-755.

55. Chen HY, Chiu YL, Hsu SP, et al. Elevated C-reactive protein level in hemodialysis patients with moderate/severe uremic pruritus: A potential mediator of high overall mortality. QJM, 2010; 103(11): 837-846.

56. Moon SJ, Kim HJ, Cho SB, et al. Epidermal proteinase-activated receptor- 2 expression is increased in end-stage renal disease patients with pruritus: A pilot study. Electrolyte Blood Press, 2014; 12(2): 74-79.

57. Markova A, Lester J, Wang J, et al. Diagnosis of common dermopathies in dialysis patients: A review and update in Seminars in dialysis. 2012. Wiley Online Library.

58. Baghel N, Awasthi S, and Kumar SS. Cutaneous manifestations in patients with chronic kidney diseases on haemodialysis. Int J Res Med Sci, 2017; 5(4): 1673-1678

59. Avermaete A, Altmeyer P, and Bacharach $\square$ Buhles M. Skin changes in dialysis patients: A review. Nephrol Dial Transpl, 2001; 16(12): 2293 2296.

60. Szepietowski JC, Reich A, and Schwartz RA. Uraemic xerosis. Nephrol Dial Transpl, 2004; 19(11): 2709-2712.

61. Dugas $\square$ Breit S, Schöpf P, Dugas M, et al. Baseline serum levels of mast cell tryptase are raised in hemodialysis patients and associated with severity of pruritus: Basale Mastzelltryptase $\square$ Serumspiegel sind bei Haemodialyse $\square$ Patienten erhöht und mit der Pruritus $\square$ Intensität assoziiert J Dtsch Dermatol Ges, 2005; 3(5): 343-347.

62. Francos GC, Kauh YC, Gittlen SD, et al. Elevated plasma histamine in chronic uremia effects of ketotifen on pruritus. Int J Dermatol, 1991; 30(12): 884-889.

63. Szepietowski J, Thepen T, Van Vloten W, et al. Pruritus and mast cell proliferation in the skin of haemodialysis patients. Inflamm Res, 1995; 44: S84-S85.

64. Prasad PVS KP, Nethra T and Kannambal. Uremic pruritus - A review. Glob Dermatol, 2015; Volume 2(6): 218-224.

65. Yosipovitch G and Samuel LS. Neuropathic and psychogenic itch. Dermatol Ther, 2008; 21(1): 32-41.

66. Twycross R, Greaves MW, Handwerker H, et al. Itch: Scratching more than the surface. QJM, 2003; 96(1): 7-26.

67. Kfoury LW and Jurdi MA. Uremic pruritus. J Nephrol, 2012; 25(5): 644-652.

68. Razeghi E, Eskandari D, Ganji MR, et al. Gabapentin and uremic pruritus in hemodialysis patients. Ren Fail, 2009; 31(2): 85-90.

69. Shavit L, Grenader T, Lifschitz M, et al. Use of pregabalin in the management of chronic uremic pruritus. J Pain Symptom Manage, 2013; 45(4) 776-781.

70. Rayner H, Baharani J, Smith S, et al. Uraemic pruritus: Relief of itching by gabapentin and pregabalin. Nephron Clin Pract, 2012; 122(3-4): $75-79$.

71. Reich A, Heisig M, Phan NQ, et al. Visual analogue scale: Evaluation of the instrument for the assessment of pruritus. Acta Derm Venereol, 2012; 92(5): 497-501.

72. Nakao K and Mochizuki H. Nalfurafine hydrochloride: A new drug for the treatment of uremic pruritus in hemodialysis patients. Drugs Today (Barc), 2009; 45(5): 323-329.

73. Reich A, Stander S, and Szepietowski JC. Pruritus in the elderly. Clin Dermatol, 2011; 29(1): 15-23.

74. Kumagai H, Ebata T, Takamori K, et al. Effect of a novel kappa-receptor agonist, nalfurafine hydrochloride, on severe itch in 337 haemodialysis patients: A Phase III, randomized, double-blind, placebo-controlled study. Nephrol Dial Transplant, 2010; 25(4): 1251-1257.

75. Tsakalos ND, Theoharides TC, Kops SK, et al. Induction of mast cell secretion by parathormone. Biochem Pharmacol, 1983; 32(2): 355-360.

76. Manenti L, Tansinda P, and Vaglio A. Uraemic pruritus: Clinical characteristics, pathophysiology and treatment. Drugs, 2009; 69(3): 251-263.

77. Gatmiri SM, Mahdavi-Mazdeh M, Lessan-Pezeshki M, et al. Uremic pruritus and serum phosphorus level. Acta Med Iran, 2013; 51(7): $477-$ 481 .

78. Manenti L, Vaglio A, and Borgatti PP. Gabapentin as a therapeutic option in uremic pruritus. Kidney Int, 2008; 73(4): 512; author reply 512-513. Metz $\mathrm{M}$ and Stander S. Chronic pruritus-pathogenesis, clinical aspect and treatment. J Eur Acad Dermatol Venereol, 2010; 24(11): 1249-1260.

80. Wikström B. Itchy skin-A clinical problem for haemodialysis patients. 
Nephrol Dial Transpl, 2007; 22(suppl 5): v3-v7.

81. Yosipovitch G, Zucker I, Boner G, et al. A questionnaire for the assessment of pruritus: Validation in uremic patients. Acta Derm Venereol, 2001; 81(2): 108-111.

82. Rayner HC, Larkina M, Wang M, et al. International comparisons of prevalence, awareness, and treatment of pruritus in people on hemodialysis. Clin J Am Soc Nephrol, 2017: CJN. 03280317.

83. Fazio SB, Yosipovitch G, Dellavalle R, et al. Pruritus: Etiology and patient evaluation. 2015, UpToDate.

84. Weisshaar E, Szepietowski JC, Darsow U, et al. European guideline on chronic pruritus. Acta Derm Venereol, 2012; 92(5): 563-586.

85. Belville RG and Seupaul RA. Pain measurement in pediatric emergency care: A review of the faces pain scale-revised. Pediatr Emerg Care, 2005; 21(2): 90-93.

86. Yosipovitch G, Greaves MW, and Schmelz M. Itch Lancet, 2003; 361(9358): 690-694.

87. Elman S, Hynan L, Gabriel V, et al. The $5 \square \mathrm{D}$ itch scale: A new measure of pruritus. Br J Dermatol, 2010; 162(3): 587-593.

88. Majeski C, Johnson J, Davison S, et al. Itch Severity Scale: A self $\square$ report instrument for the measurement of pruritus severity. Br J Dermatol, 2007; 156(4): 667-673.

89. Chren M-M, Lasek RJ, Quinn LM, et al. Skindex, a quality-of-life measure for patients with skin disease: Reliability, validity, and responsiveness. J Invest Dermatol, 1996; 107(5).

90. Chren M-M, Lasek RJ, Flocke SA, et al. Improved discriminative and evaluative capability of a refined version of Skindex, a quality-oflife instrument for patients with skin diseases. Arch Dermatol, 1997 133(11): 1433-1440.

91. Chren M-M, Lasek RJ, Sahay AP, et al. Measurement properties of Skindex-16: A brief quality-of-life measure for patients with skin diseases. J Cutan Med Surg, 2001; 5(2): 105-110.

92. Furue M, Ebata T, Ikoma A, et al. Verbalizing extremes of the vsual analogue scale for pruritus: A consensus statement. Acta Derm Venereol, 2013; 93(2): 214-215.

93. Reich A, Bożek A, Janiszewska K, et al. 12-Item Pruritus Severity Scale: Development and validation of new itch severity questionnaire. BioMed Res Int, 2017; 2017.

94. Phan NQ, Blome C, Fritz F, et al. Assessment of pruritus intensity: Prospective study on validity and reliability of the visual analogue scale, numerical rating scale and verbal rating scale in 471 patients with chronic pruritus. Acta Derm Venereol, 2012; 92(5): 502-507.

95. Reich A, Heisig M, Phan NQ et al. Visual analogue scale: Evaluation of the instrument for the assessment of pruritus. Acta Derm Venereol, 2012; 92(5): 497-501.

96. Medscape. Pruritus intensity assessment: Challenge for clinicians Unidimensional scales for itch severity measurement; Available from: https://www.medscape.org/viewarticle/804771 4 [Accessed 23rd November 2018]

97. Darsow U, Scharein E, Simon D, et al. New aspects of itch pathophysiology: Component analysis of atopic itch using the 'Eppendorf Itch Questionnaire'. Int Arch Allergy Immunol, 2001; 124(1-3): 326-331.

98. Finlay AY and Khan G. Dermatology life Quality Index (DLQI) simple practical measure for routine clinical use. Clin Exp Dermatol, 1994; 19(3): 210-216.

99. Both H, Essink-Bot M-L, Busschbach J, et al. Critical review of generic and dermatology-specific health-related quality of life instruments. J Invest Dermatol, 2007; 127(12): 2726-2739.

100. Chren M-M. The Skindex instruments to measure the effects of skin disease on quality of life. Dermatol Clin, 2012; 30(2): 231-236.

101. Lee EH, Klassen AF, Nehal KS, et al. A systematic review of patientreported outcome instruments of nonmelanoma skin cancer in the der- matologic population. J Am Acad Dermatol, 2013; 69(2): e59-e67.

102. Whited JD, Warshaw EM, Edison KE, et al. Effect of store and forward teledermatology on quality of life: A randomized controlled trial. JAMA Dermatol, 2013; 149(5): 584-591.

103. Mirza R, Wahid Z, and Talat H. Dermatological manifestation in chronic renal failure patients on haemodialysis. J Liaquat Univ Med Health Sci, 2012; 11(1): 24-28

104. Sheikh M, Malik LM, and Jahangir M. Cutaneous manifestations of chronic renal failure. J Pak Assoc Dermatol, 2016; 24(2): 150-155.

105. Ying SC and Krishnan M. Interpretation of quality of life outcomes amongst end stage renal disease patients in selected hospitals of Malaysia. Int J Pharm Sci Res, 2014; 5(1): 60.

106. Jin D-h, Shen H-y, Feng S, et al. Treatment effects of different incident dialysis modalities on pruritus in elderly uremic patients. Int J Gerontol, 2014; 8(4): 223-227.

107. Jha V. Current status of end-stage renal disease care in India and Pakistan. Kidney Int Suppl, 2013; 3(2): 157-160.

108. Saeed F, Ahmad M, Alam SM, et al. Chronic kidney disease - A multi-center study in Karachi, Pakistan. Int J Pharm Pharm Sci, 2017; 9(12): 170-174.

109. Al-Naggar RA, Osman MT, Ismail N, et al. Diabetes mellitus among selected Malaysian population: A cross-sectional study. Int J Med Res Health Sci, 2017; 6(4): 1-11

110. Ambigapathy R, Ambigapathy S, and Ling H,. A knowledge, attitudand practice (KAP) study of diabetes mellitus among patients attending Klinik Kesihatan Seri Manjung. NCD Malaysia, 2003; 2(2): 6-16.

111. Ng SH, Chan KH, Lian ZY, et al. Reality vs illusion: Knowledge, attitude and practice among diabetic patients. Int J Collab Res Intern Med Public Health, 2012; 4(5): 723

112. Abdul-Razak S, Daher AM, Ramli AS, et al. Prevalence, awareness, treatment, control and socio demographic determinants of hypertension in Malaysian adults. BMC Public Health, 2016; 16(1): 351.

113. Zuhaid M, Zahir KK, and Diju IU. Knowledge and perceptions of diabetes in urban and semi urban population of Peshawar, Pakistan J Ayub Med Coll Abbottabad, 2012; 24(1): 105-108.

114. Gillani A, Amirul Islam F, Hayat K, et al. Knowledge, attitudes and practices regarding diabetes in the general population: A cross-sectional study from Pakistan. Int J Environ Res Public Health, 2018; 15(9): 1906.

115. Irshad M, Khan I, Khan FA, et al. A survey of awareness regarding diabetes and its management among patients with diabetes in Peshawar, Pakistan. J Postgrad Med Inst, 2015; 28(4).

116. Almas A, Godil SS, Lalani S, et al. Good knowledge about hypertension is linked to better control of hypertension: A multicentre cross sectional study in Karachi, Pakistan. BMC Res Notes, 2017; 24(5): 579 .

117. Anees M, Mumtaz A, Nazir M, et al. Referral pattern fof hemodialysis patients to nephrologists. JCPSP-J Coll Physici 2007; 17(11): 671-674.

118. Zaki MR, Ghazanfar A, Hussain S, et al. Presentations, etiology and outcome of patients with Chronic Renal Failure admitted at Urology Department, Mayo Hospital Lahore-A retrospective analysis of 1257 patients over a period of 10 years. Ann King Edw Med Univ, 2003; 9(1)

119. Shafi ST, ul Haq R, and Shafi T. Adequacy of hemodialysis and laboratory parameters in patients at Shaikh Zayed medical complex hemodialysis center, Lahore. Proceeding SZPGMI vol 2003; 17(1) 7-12.

120. Anees M and Ibrahim M. Anemia and hypoalbuminemia at initiation of hemodialysis as risk factor for survival of dialysis patients. J Coll Physicians Surg Pak, 2009; 19(12): 776-780. 